Www.jmscr.igmpublication.org

Impact Factor (SJIF): 6.379

Index Copernicus Value: 79.54

ISSN (e)-2347-176x ISSN (p) 2455-0450

crossrefDOI: https://dx.doi.org/10.18535/jmscr/v6i8.186

Journal Of Medical Science And Clinical Research

IGM Publication

An Official Publication of IGM Publication

\title{
Atypical Presentation of Leprosy with Non-Healing Fissure and Ulcer of Left Lower Limb
}

\author{
Authors \\ Chevigoni Saidulu', Nandyala Venkateswarlu M. D², Prodduturi Gandiah M. D³, \\ Gubba Pradeep ${ }^{4}$ \\ ${ }^{1}$ Post-graduation - General Medicine, ${ }^{2}$ Professor and HOD of Medicine \\ ${ }^{3}$ Professor and Director of Post Graduate education of Medicine, ${ }^{4}$ Assistant Professor - General Medicine \\ Sri Venkata Sai Medical College, Mahabubnagar, Telangana, India
}

\begin{abstract}
Leprosy exhibits a wide spectrum of presentations, varying from the tuberculoid to the lepromatous pole, with immunologically unstable borderline forms in-between, depending on immune status of the individual. Leprosy can have a diverse manifestation of skin and peripheral nervous system. Occasionally perplexing presentations are seen. Oedema which is described as a symptom of reactional states, may occur during the course of leprosy. Both diagnosis and adequate treatment are important as failure to do so results in permanent damage. Oedema though it is a neglected subject in leprosy, it is not uncommon in patients with lepra reactions, both type 1 and type 2. Herein we report a case with bilateral pitting pedal oedema as the presenting manifestation of leprosy, shortness of breath, non healing fissure and ulcer on left lateral foot.
\end{abstract}

Keywords: Atypical manifestation, nonhealing fissure and ulcer, oedema.

\section{Introduction}

Leprosy is a nonfatal, slowly progressive, chronic infectious disease caused by the bacillus mycobacterium leprae. It is exclusively a disease of developing world with high prevalence in rural residence. The transmission routes are multiple, commonly with nasal droplet infection, contact with infected soil and vector transmission. It is a serious, mutilating and stigmatizing disease. It is highly infective, but has low pathogenicity and low virulence with a long incubation period. Its clinical manifestations are largely confined to cold areas like skin, peripheral nervous system, upper respiratory tract, eyes and testes. The diagnosis of leprosy is made from the clinical picture, but must be complimented by bacteriological and histopathological analyses.

\section{Case report}

A male patient of age 45 years presented to us with complaints bilateral pedal oedema and a nonhealing fissure and ulcer on lateral side of his left foot.

The oedema is bilateral and of pitting type extending up to the knee with no diurnal variation and no reliving factors. The patient has a deep fissure and an ulcer on the lateral side of his left foot for 6 months which is none healing. On examination the patient was conscious, cooperative, moderately built and moderately 
nourished, his vitals were pulse 82beats/min, blood pressure 130/90mmof hg and GRBS $112 \mathrm{mg} / \mathrm{dl}$. There are multiple hypopigmented patches distributed all over the body. The patient has madarosis, along with infiltration on the forehead and earlobes. Congestion of the nasal mucosa is noted. Peripheral nerves including the bilateral ulnar and radial and left supra clavicular, lateral cutaneous and lateral popliteal nerve thickenings are seen. The ulnar nerve associated clawing of the fingers is observed. There is resorption of digits, glove and stocking anaesthesia and loss of cold sensation.

On further workup, hemogram was normal with haemoglobin $-11.2 \mathrm{gm} / \mathrm{dl}$ and total leucocyte
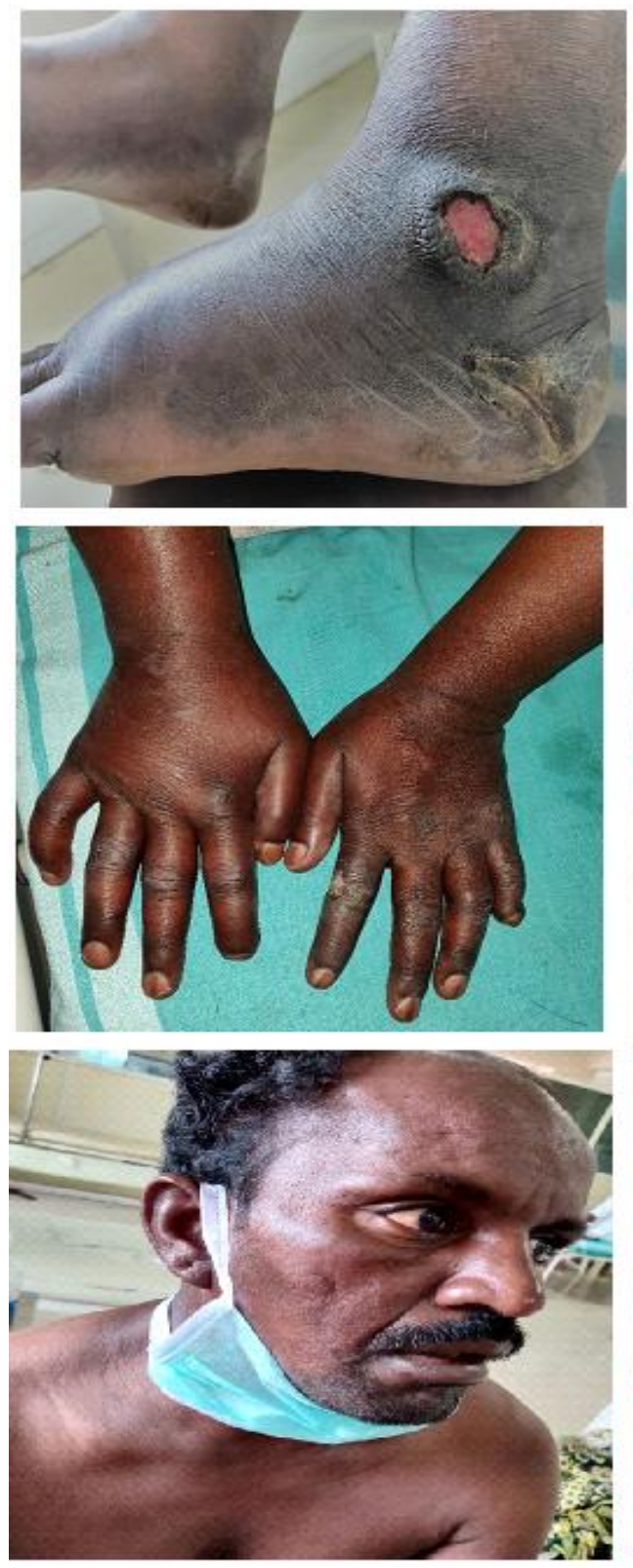

count - 5,800.USG abdomen and 2D-eco had a normal study. In the liver parameters there is reversal of albumin and globulin ratio with normal total proteins. Screening for HIV and HBsAg is negative. Renal parameters were normal. Split skin smear disclosed numerous bacilli and lepromin test was negative.

The patient was started on a stat dose of rifampicin $600 \mathrm{mg}$, clofazimine $300 \mathrm{mg}$, dapsone $100 \mathrm{mgfollowed}$ by clofazimine $50 \mathrm{mg} /$ day, dapsone 100mg/day and rifampicin 600mg/ monthly, clofazimine $300 \mathrm{mg} / \mathrm{monthly}$ under supervision.
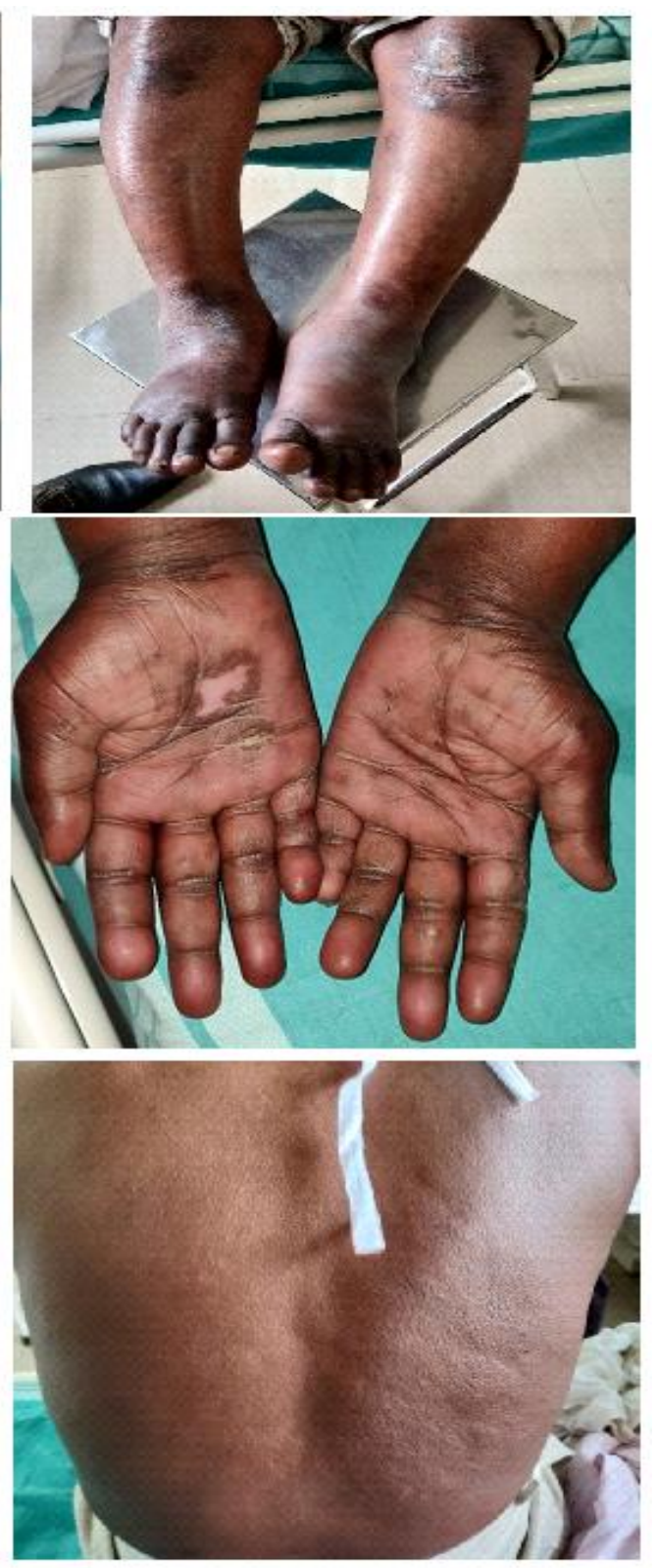

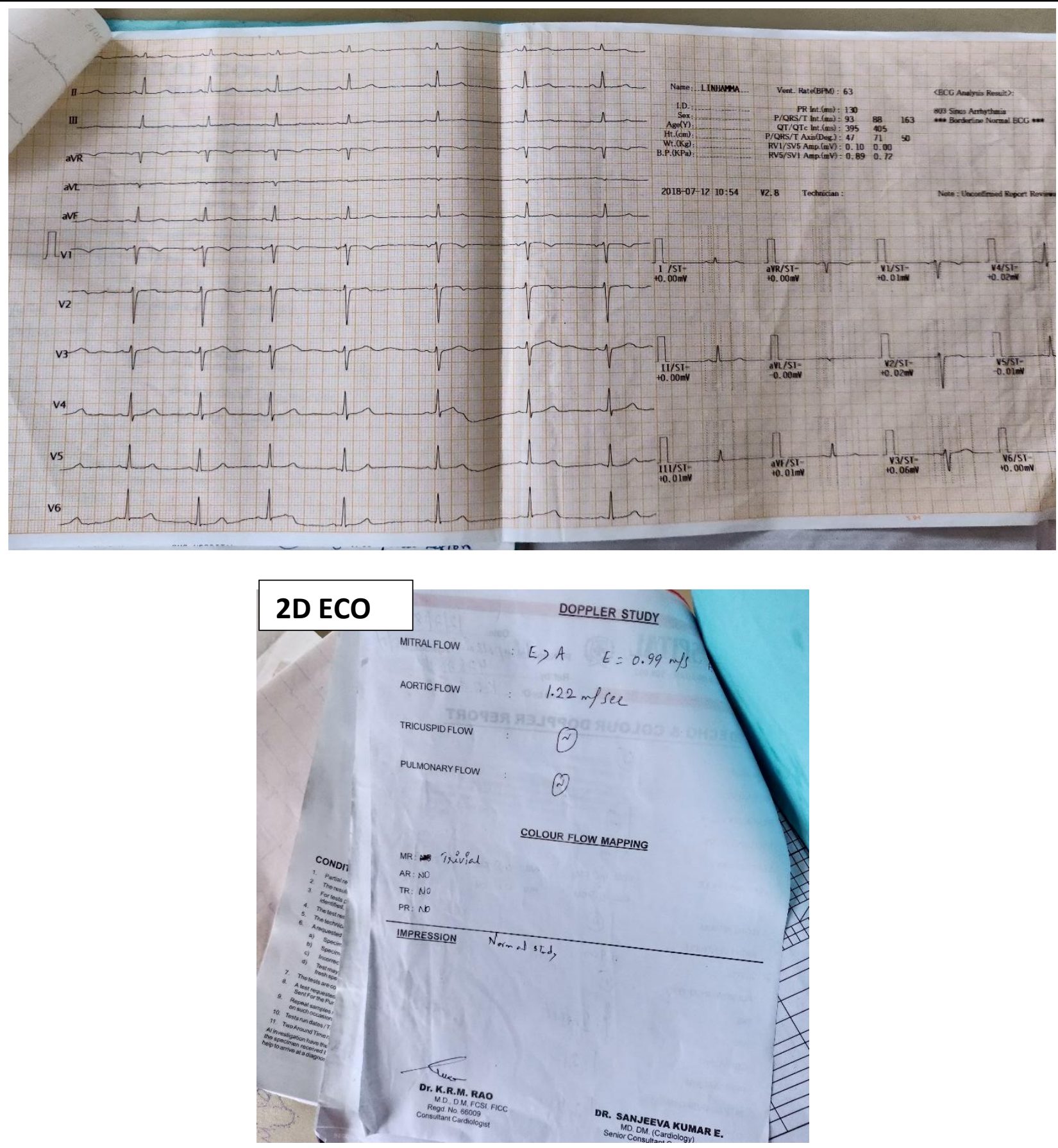

\section{Discussion}

Leprosy is contagious and chronic systemic granulomatous disease. The case lode has drastically come down with worldwide application of multi-drug therapy, but still cases continue to be detected.The mycobacterium has a preference for peripheral tissue, as it appears to survive better at a temperature close to $30{ }^{\circ} \mathrm{C}$, hence it affects the skin and peripheral nerves. This is an atypical presentation of leprosy with bilateral pedal oedema and nonhealing ulcer and fissure. Thepatient was evaluated for all the possible cause of lower limb oedema, but with the renal and cardiac parameter being normal sever coditions are rulled out. Aditionally the supporting factors like positivity of the split skin smear, nerve thickenings and cutaneous changes made the diagnosis of leprosy more simple.

In this case oedema is caused by, the damage to autonomic nerves caused increased capillary permeability, large number of bacilli invading the endothelial lining and damage to the blood vessel walls during immune-complex reactions. The dysnea is due to cogested and oedematous nasal 
mucosa and the involvement of respiratory tract.nonhealing ulcer and fissure are due to chronic venous congestion and peripheral neuropathy leading to insensitivity for trauma respectively
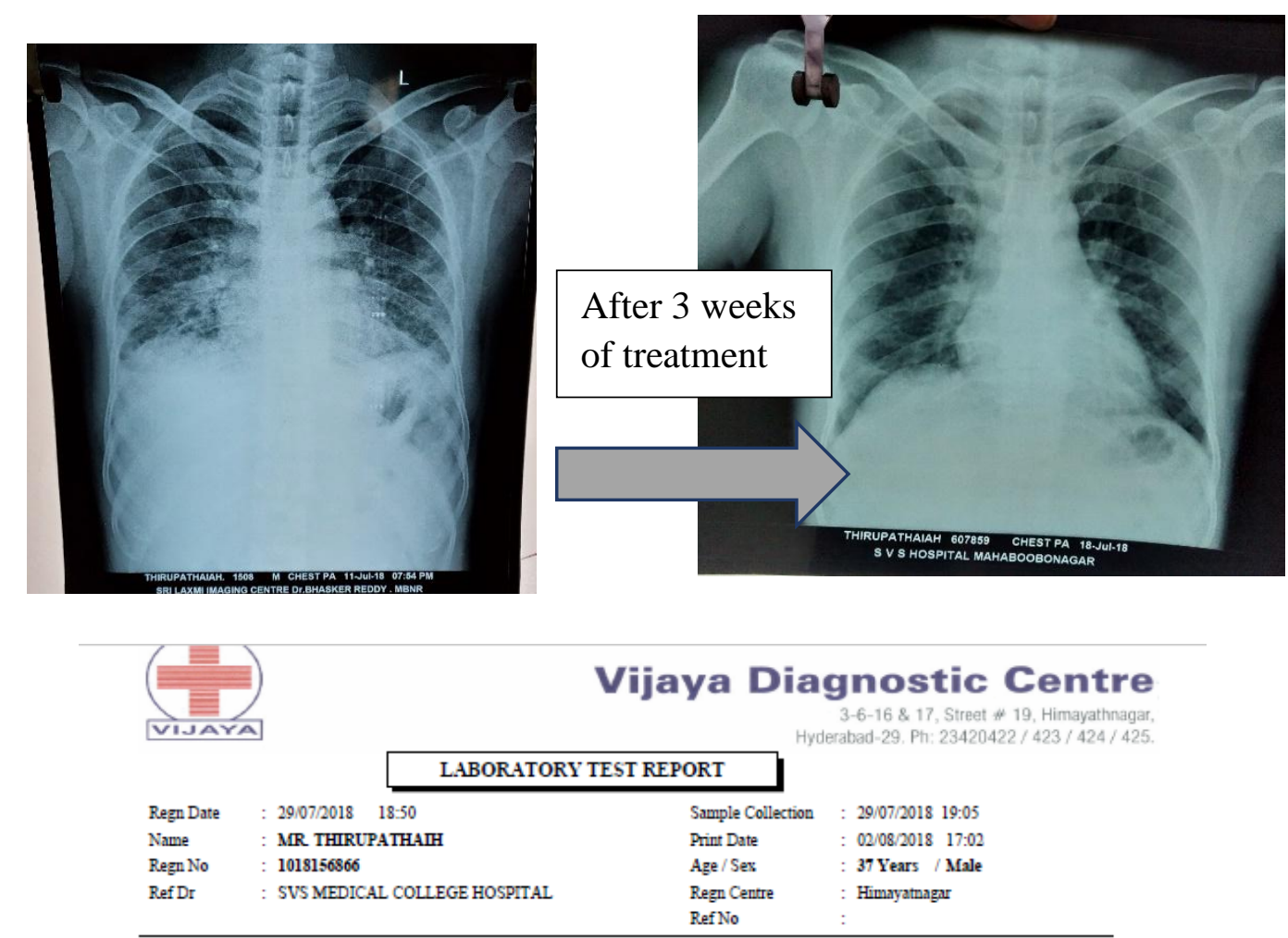

HISTOPATHOLOGY REPORT (SMLALL BIOPSY)

Biopsy No. $8093 / H-18 / 6866$

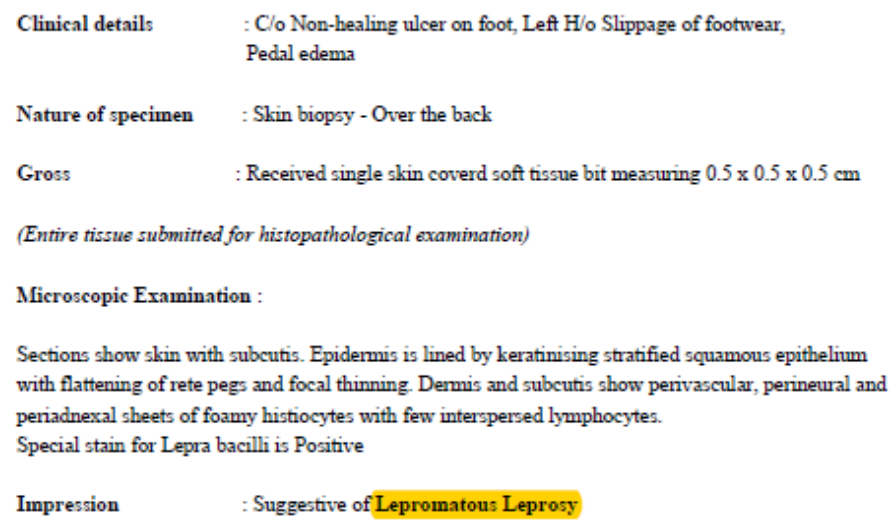

It is clear that patients immune status is of key importance as regards to the clinical manifestations of leprosy.the diagnosis of the case and prompt treatment are prerequisites for a salutary outcome of the disease.

\section{Conclusion}

In the current scenario, when the leprosy is considered as eliminated in india and patients coming with typical signs have become a rarity, a high index of clinical suspicion is necessary so as to not miss out on cases with atypical presentation. It is difficult to perform a 
histopathological examination in each case. However, slit skin smear from selective sites, which is a relatively minor procedure, should always be done in suspected leprosy cases. The most important factor to prevent adverse patient outcome is education of the people in endemic areas about the varied symptoms of the disease, and prompt recognition and initiation of multidrug regimen by the health care providers, follow up is very essential.

\section{References}

1. Hegde SP, Shenoy MM, Pinto M, Amin VB. Leprosy: Chronicles of a disabling disease. Arch Med Health Sci 2015;3: 346- 9

2. Ooi WW, Srinivasan J. Leprosy and the peripheral nervous system: Basic and clinical aspects. Muscle Nerve 2004;30:393- 409.

3. World Health Organization. Global Leprosy Strategy 2016- 2020: Accelerating Towards a Leprosy- Free World. Geneva: World Health Organization; 2016. p. 3- 4

4. Pinheiro RO, de Souza Salles J, Sarno EN, Sampaio EP. Mycobacterium leprae- host- cell interactions and genetic determinants in leprosy: An overview. Future Microbiol 2011;6:217- 30.

5. Medeiros RC, Girardi KD, Cardoso FK, Mietto BS, Pinto TG, Gomez LS, et al. Subversion of schwann cell glucose metabolism by Mycobacterium leprae. J Biol Chem 2016;291:21375- 87..

6. Scollard DM. The biology of nerve injury in leprosy. Lepr Rev 2008;79:242- 53.

7. Prasad PV, editor. All about Leprosy. New Delhi: Jaypee Brothers Medical Publishers (P) Ltd.; 2005.

8. Kumar B, Pradhan A. Fine needle aspiration cytology in diagnosis of pure neuritic leprosy. Patholog Res Int 2011;2011:158712.
9. Raval RC. Various faces of Hansen's disease. Indian J Lepr 2012;84:155- 60.

10. Kim SH, Shin HY, Kim SM, Kwon KH, Minn YK. Leprotic neuropathy misdiagnosed as chronic inflammatory demyelinating polyneuropathy. Lepr Rev 2012;83:93- 7.

11. Andrade LR, Jardim MR, Pitta IJ, Giesel LM, Silveira RC, Vital RT, et al. Chronic inflammatory demyelinating polyneuropathy in a patient with a leprosy reversal reaction: A case report. Arch Infect Dis Ther 2017;1:1- 3.

12. Smith CS, Aerts A, Saunderson P, Kawuma J, Kita E, Virmond M, et al. Multidrug therapy for leprosy: A game changer on the path to elimination. Lancet Infect Dis 2017;17:e293- 97. 